\title{
Ambiguous Geochemical Signature of the Ejecta of Lonar Crater, India
}

Arif M. Sikder1, Newsom Horton2, Saumitra Misra3, Jose Brum4, Tina Hill5, Xin-Chen Liu1, Joseph B. McGee Turner6

1. Center for Environnemental Studies (CES), Virginia Commonwealth University (VCU)

2. University of New Mexico, Institute of Meteoritics and Dept. of Earth and Planetary Sciences,

3. Department of Geology, University of Kwazulu-Natal, South Africa

4. Olympus Scientific Solutions Americas

5. Bruker AXS Inc.

6. Department of Chemistry, Virginia Commonwealth University (VCU) 


\section{Lonar Crater: India}

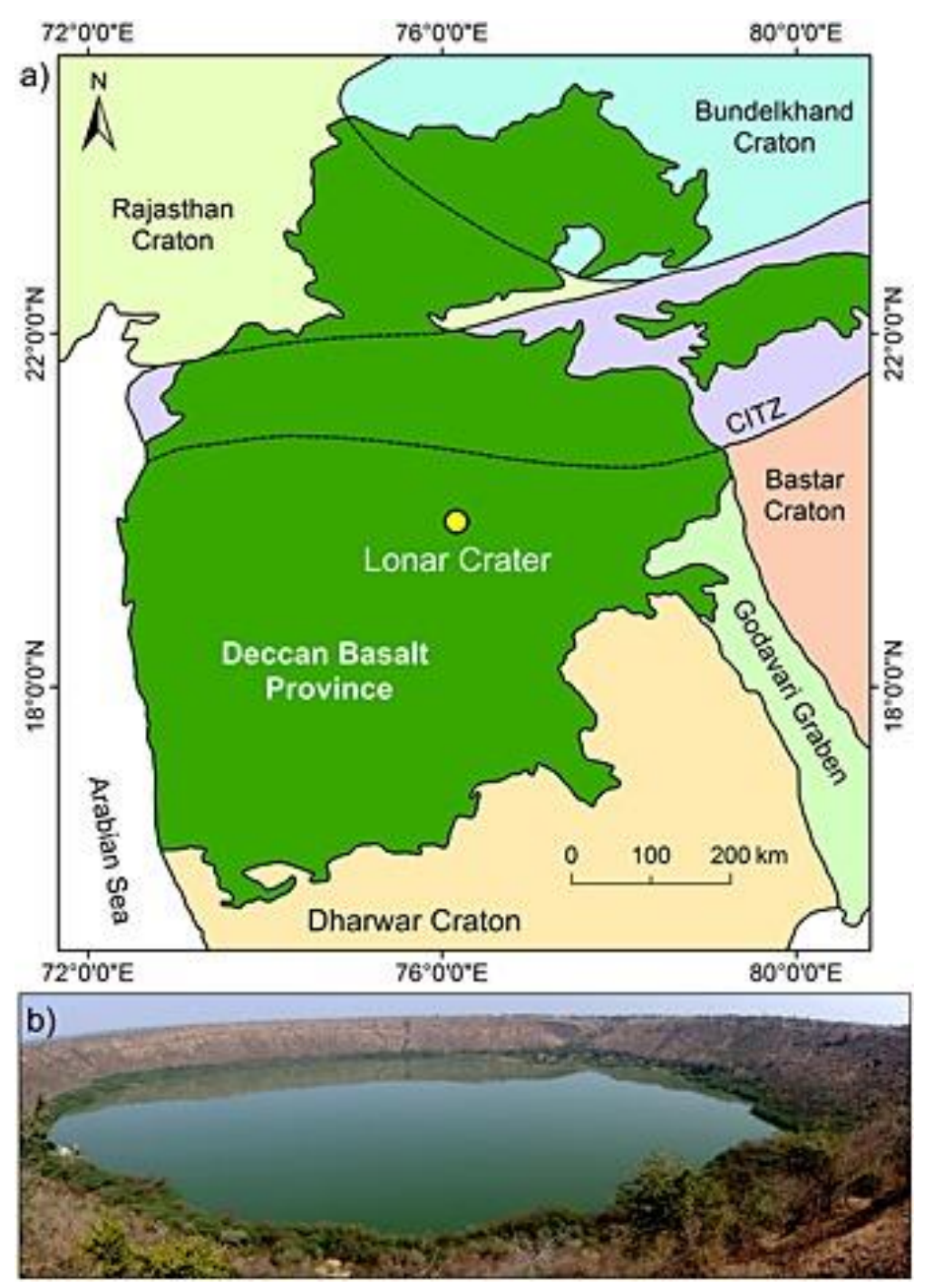

The Deccan Traps are one of the largest volcanic provinces in the world, consisting of more than 2-kmthick flat-lying basalt lava flows covering an area of nearly 500,000 $\mathrm{km} 2$ in west-central India; estimates of the original area covered by the lava flows are as high as 1.5 million $\mathrm{km} 2$, and the volume of basalt is estimated at $\sim 0.5$ million km3 (e.g., Mahoney 1988; Cox and Hawkesworth 1985; Widdowson et al. 2000). 


\section{Lonar Crater: India}

The Deccan basalts were irrupted between $\sim 69$ and $63 \mathrm{Ma}$ ago, with a main peak in activity around 66 to $65 \mathrm{Ma}$ (Pandey, 2002 and Courtillot and Renne 2003). Six basalt flows, ranging in thickness between $\sim 8$ and $40 \mathrm{~m}$, are seen in and around Lonar village, while four flows are exposed on the crater wall (Ghosh and Bhaduri 2003).

The comparatively young $(50,000$ years old) Lonar crater of India is presumably one of the two known terrestrial impact craters that emplaced about 65 million years old Deccan basalt.

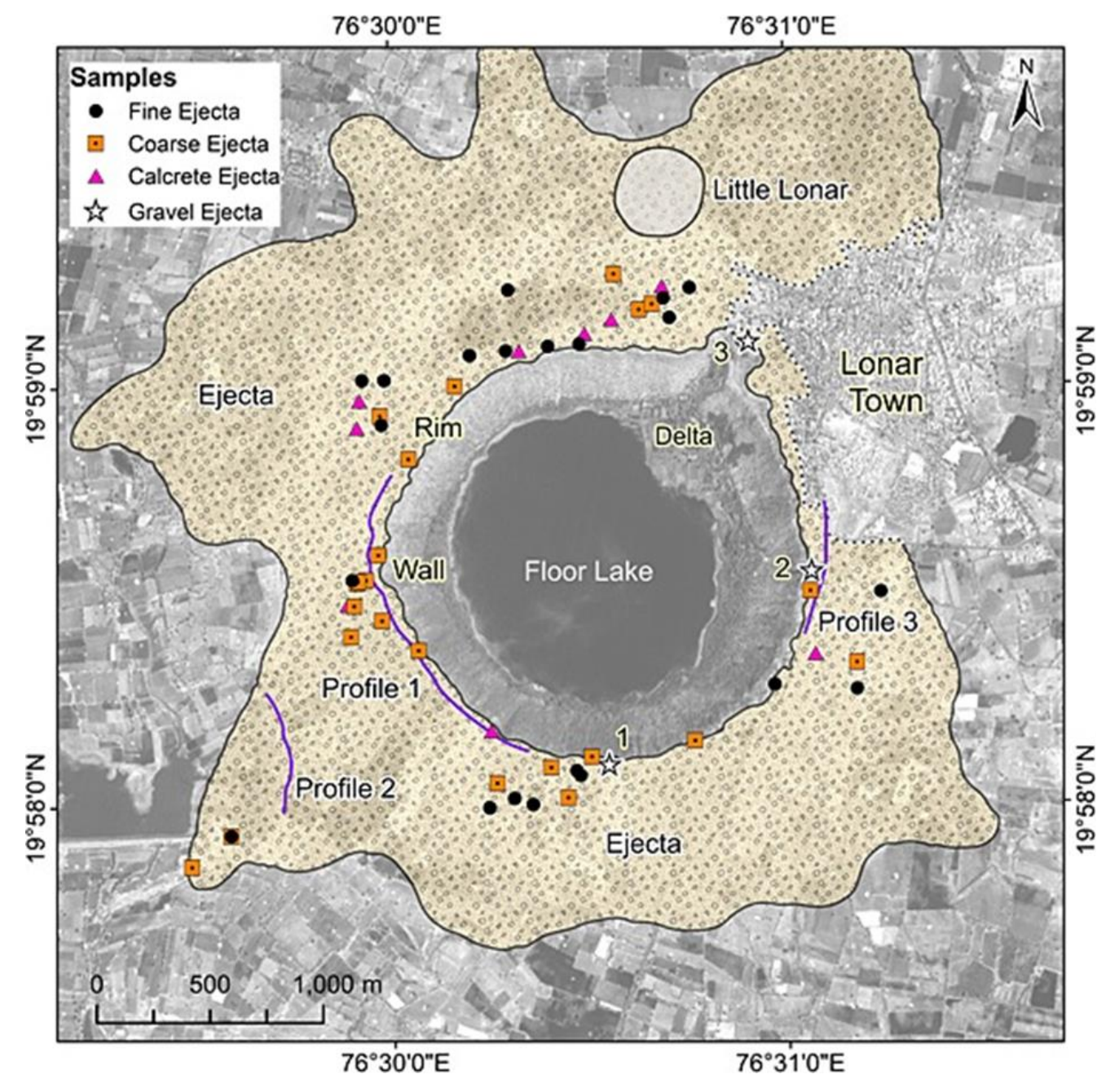

Indian Space Research Organisation's Cartosat image of Lonar Crater showing the locations of ejecta samples. 


\section{Geologic setting}

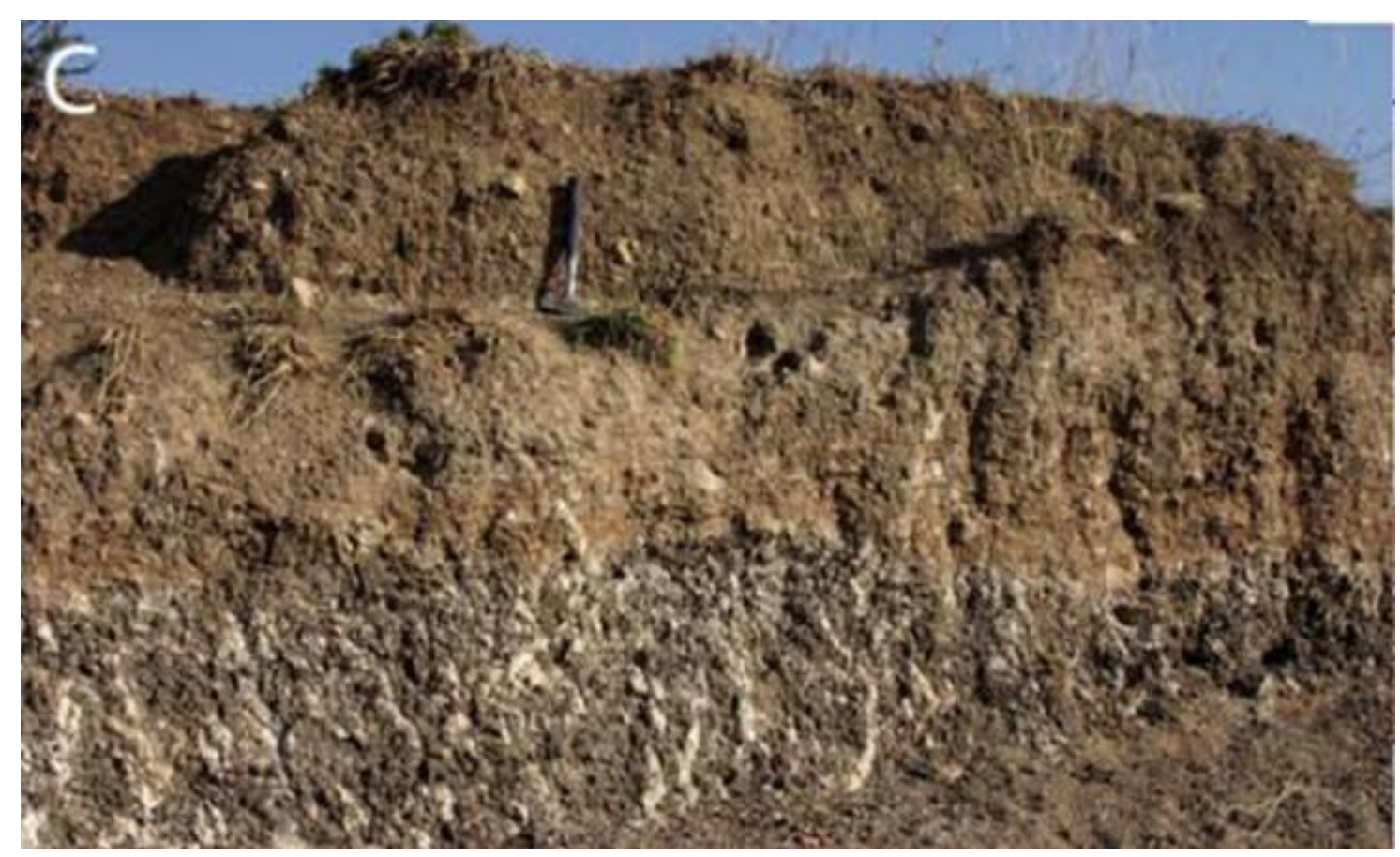

The impact cratering occurred tens of million years after the formation of the Deccan Basalt and it is very likely that in the meantime the postulated target basalts layers were extensively altered due to weathering.

The presence of caliche, a carbonate-rich material at the base of the impact deposits. 


\section{Geologic setting}
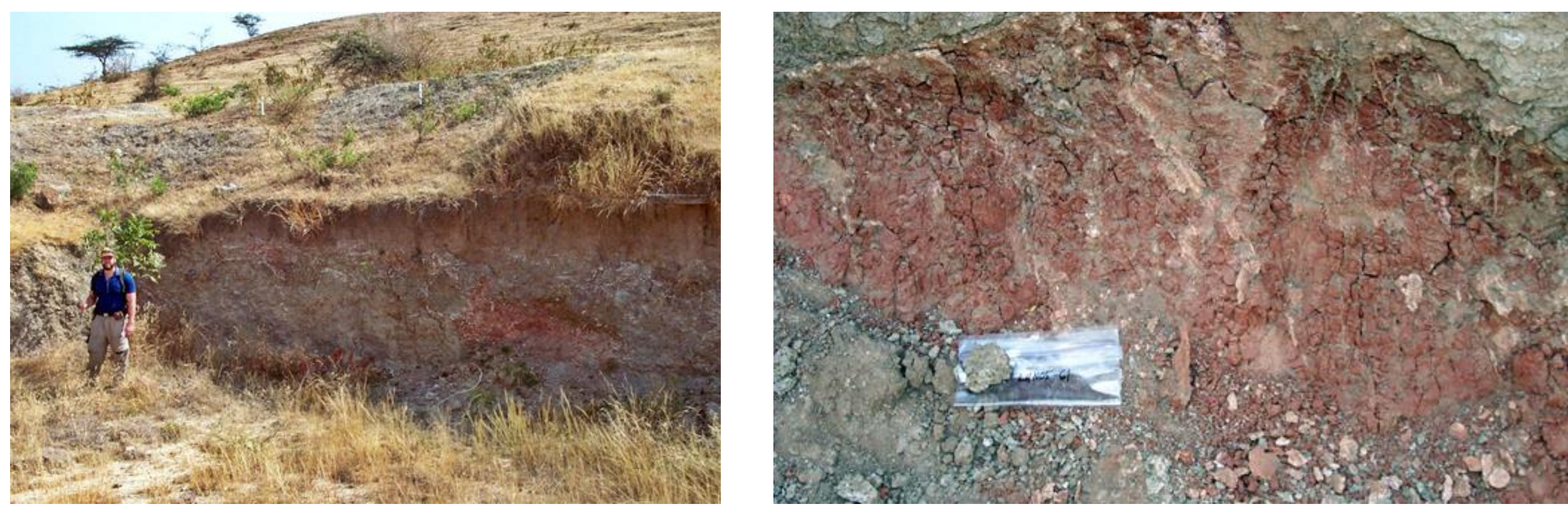

Reb bole laterally continuous in Deccan Plateau extensively cemented by veins of quartz and zeolite. The zeolite was identified to be of heulandite by the earlier workers.

Amygdules, present in some of the vesicles are green zeolite, white calcite, and/or translucent gray quartz (based on preliminary microprobe analysis). 


\section{LHN05 - 54}

\section{Preimpact Altered Rock}

\begin{tabular}{|l|l|r|r|r|r|r|r|r|r|}
\hline Sample Code & Sample Type & $\mathrm{Ba}$ & $\mathrm{Cr}$ & $\mathrm{Co}$ & $\mathrm{Ni}$ & $\mathrm{Cu}$ & $\mathrm{Zn}$ & $\mathbf{N i} / \mathbf{C r}$ & $\mathbf{C o} / \mathbf{C r}$ \\
\hline LHN 05-54 & Preimpact alterted Basalt & $\mathbf{1 5 6}$ & 50 & 40 & 40 & $\mathbf{2 1 0}$ & $\mathbf{8 0}$ & $\mathbf{0 . 8}$ & $\mathbf{0 . 8}$ \\
\hline
\end{tabular}
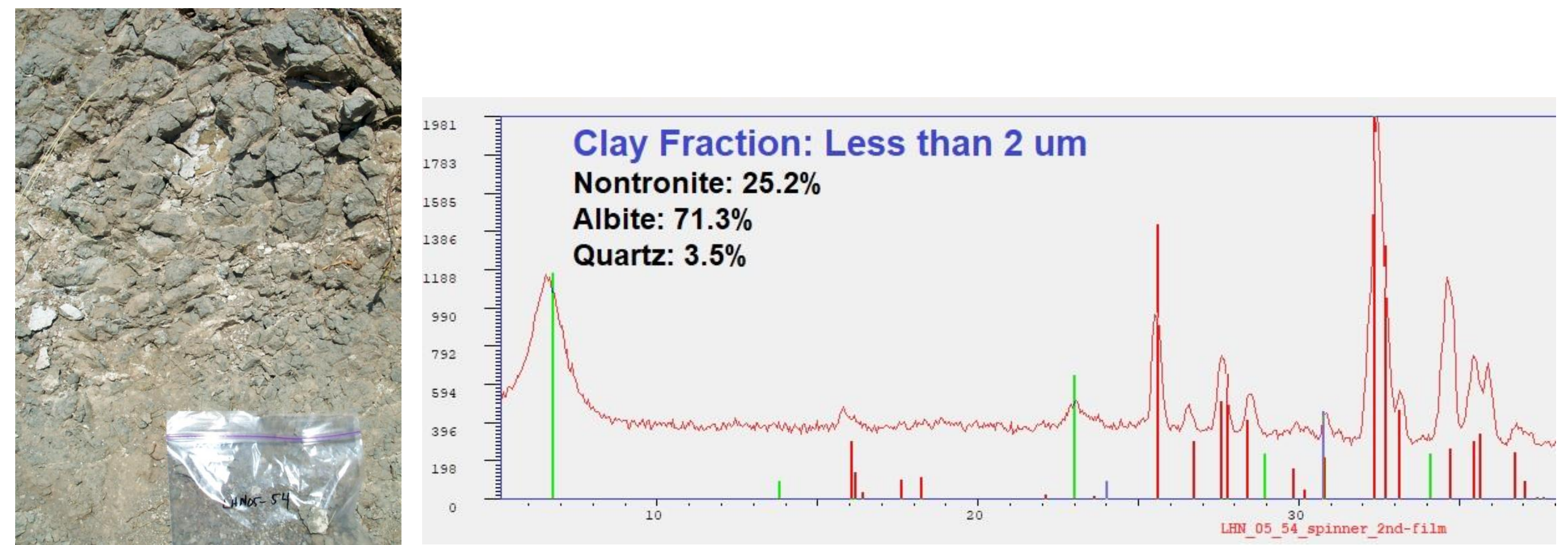


\section{LHN $05-65$ Impact Melt, Glass locality, parts of single big clast}
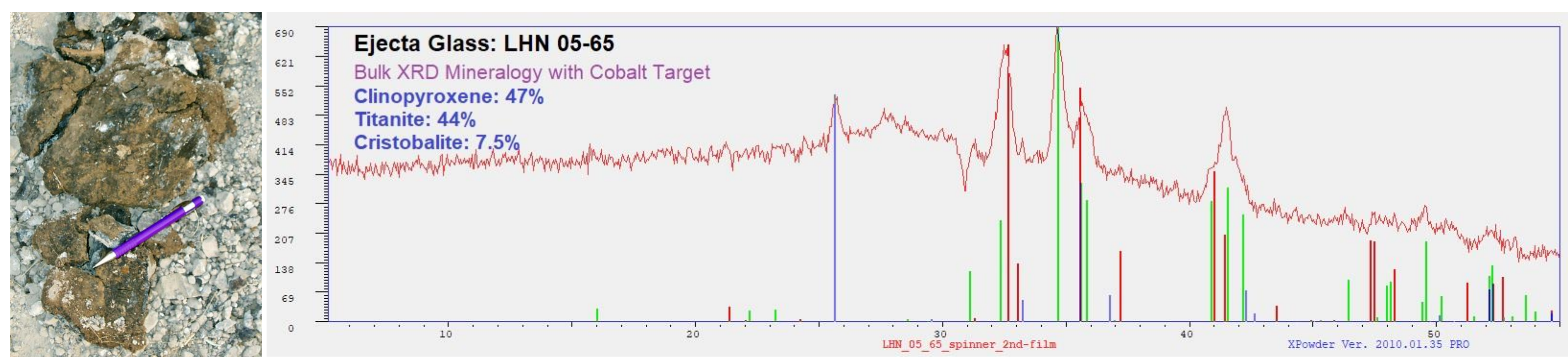

\begin{tabular}{|l|l|r|r|r|r|r|r|r|r|}
\hline Sample Code & Sample Type & $\mathrm{Ba}$ & $\mathrm{Cr}$ & $\mathrm{Co}$ & $\mathrm{Ni}$ & $\mathrm{Cu}$ & $\mathrm{Zn}$ & $\mathrm{Ni} / \mathrm{Cr}$ & $\mathrm{Co} / \mathrm{Cr}$ \\
\hline LHN 05-65 & Impact melt glass & $\mathbf{2 1 8}$ & 80 & 44 & 70 & $\mathbf{2 0 0}$ & $\mathbf{1 3 0}$ & $\mathbf{0 . 8 7 5}$ & $\mathbf{0 . 5 5}$ \\
\hline
\end{tabular}




\section{LC-05-SEB-026 Fresh side of Boulder}

\begin{tabular}{|l|l|r|r|r|r|r|r|r|r|}
\hline Sample Code & Sample Type & $\mathrm{Ba}$ & $\mathrm{Cr}$ & $\mathrm{Co}$ & $\mathrm{Ni}$ & $\mathbf{C u}$ & $\mathbf{Z n}$ & $\mathrm{Ni} / \mathrm{Cr}$ & $\mathrm{Co} / \mathrm{Cr}$ \\
\hline LC-05-SEB-026 & Boulder & $\mathbf{1 5 9}$ & $\mathbf{7 0}$ & $\mathbf{4 6}$ & $\mathbf{6 0}$ & $\mathbf{2 1 0}$ & $\mathbf{1 3 0}$ & $\mathbf{0 . 8 5 7}$ & $\mathbf{0 . 6 5 7}$ \\
\hline
\end{tabular}

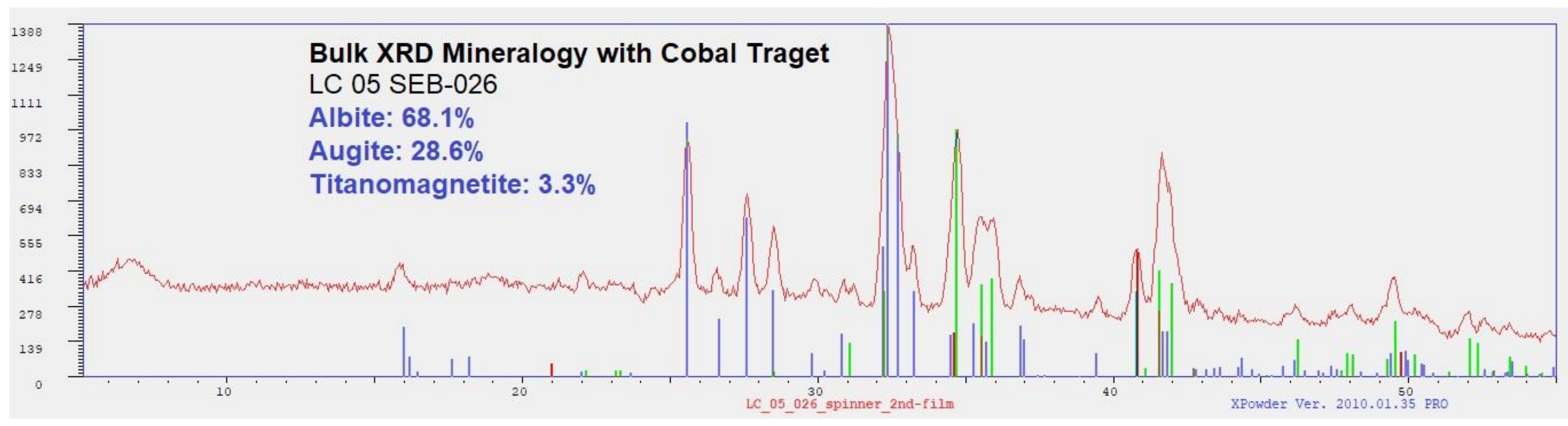




\section{Ejecta of South Western Rim (L2)}

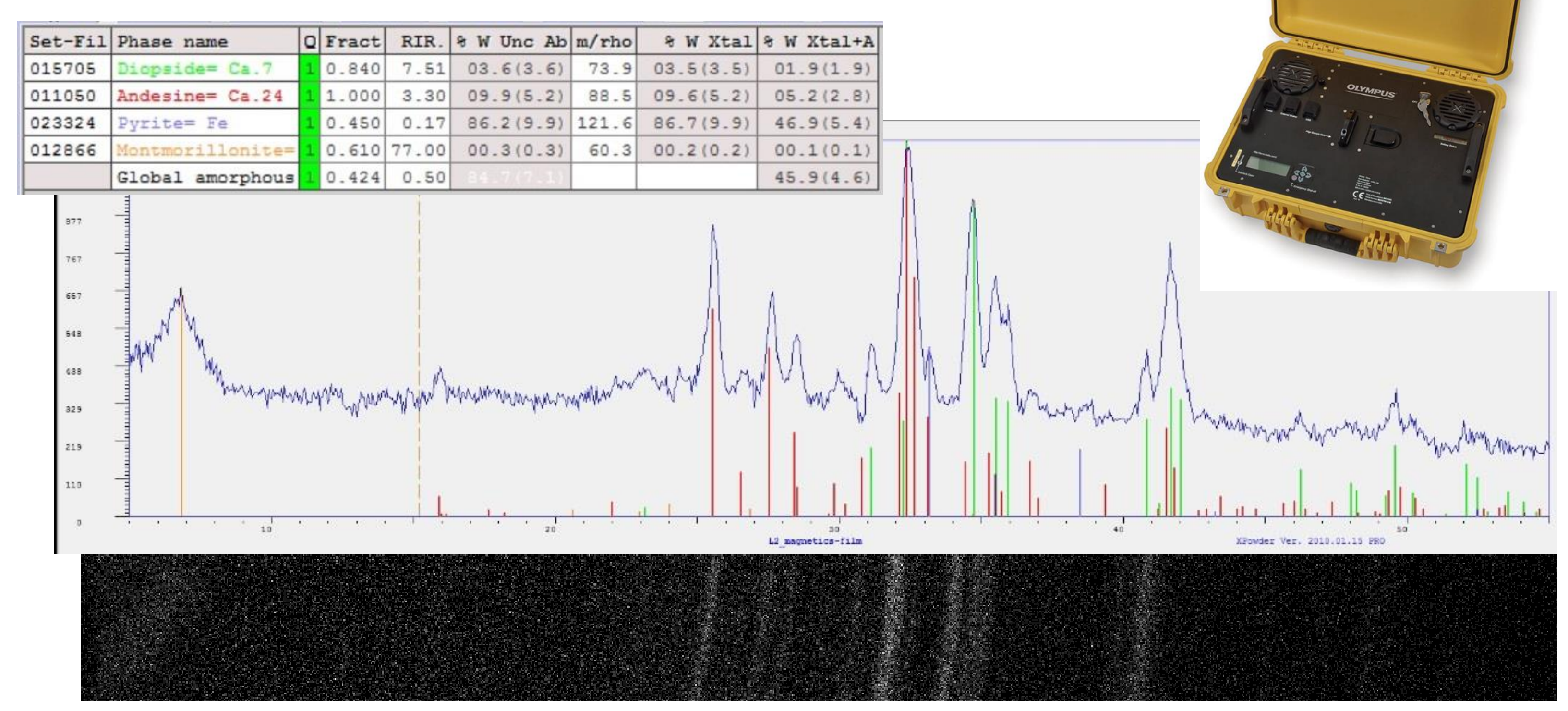




\section{Ejacta Samples of Kalapani}

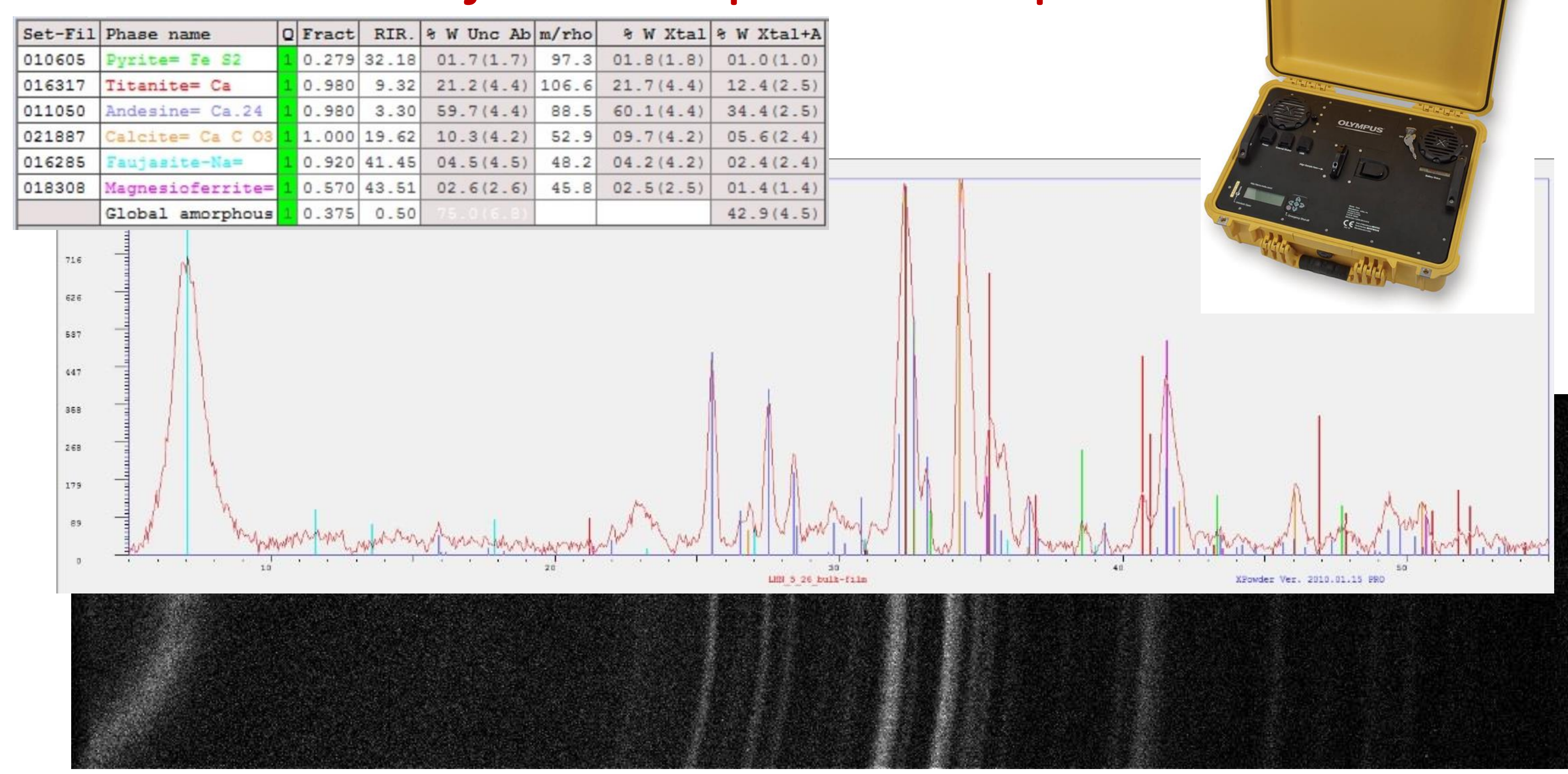




\section{Results INAA Analysis}

Higher vale of $\mathrm{Ni} / \mathrm{Cr}$ and $\mathrm{Co} / \mathrm{Cr}$ in the sample of altered basalt

\begin{tabular}{|c|c|c|c|c|c|c|c|c|c|}
\hline Sample Code & Sample Type & $\mathrm{Ba}$ & $\mathrm{Cr}$ & Co & $\mathrm{Ni}$ & $\mathrm{Cu}$ & $\mathrm{Zn}$ & $\mathrm{Ni} / \mathrm{Cr}$ & $\mathrm{Co} / \mathrm{Cr}$ \\
\hline LHN 05-65 & Impact melt glass & 218 & 80 & 44 & 70 & 200 & 130 & 0.875 & 0.55 \\
\hline L 2 BULK & Bulk Ejecta & 148 & 80 & 33 & 50 & 50 & 80 & 0.625 & 0.413 \\
\hline LHN 04-8 & Bulk Ejecta & 124 & 100 & 39 & 50 & 150 & 110 & 0.5 & 0.39 \\
\hline LHN 05-26 & Bulk Ejecta & 105 & 60 & 34 & 50 & 150 & 90 & 0.833 & 0.567 \\
\hline L244 B & Bulk Ejecta & 281 & 70 & 36 & 60 & 140 & 80 & 0.857 & 0.514 \\
\hline$L-60$ & Shocked Basalt & 111 & 140 & 53 & 80 & 170 & 200 & 0.571 & 0.379 \\
\hline LHN 05-51 & Altered Basalt & 243 & 30 & 38 & 40 & 240 & 80 & 1.333 & 1.267 \\
\hline LC-05-SEB-026 & \begin{tabular}{|l} 
Boulder \\
\end{tabular} & 159 & 70 & 46 & 60 & 210 & 130 & 0.857 & 0.657 \\
\hline LHN 05-54 & \begin{tabular}{|l|} 
Preimpact alterted Basalt \\
\end{tabular} & 156 & 50 & 40 & 40 & 210 & 80 & 0.8 & 0.8 \\
\hline LC 09-261 & Paleosol & 91 & 120 & 29 & 70 & 150 & 80 & 0.583 & 0.242 \\
\hline LC 09-264 & Paleosol & 83 & 70 & 42 & 50 & 210 & 80 & 0.714 & 0.6 \\
\hline
\end{tabular}




\section{$\mathrm{Cl}$ Normalized REE Fingerpring}

1000

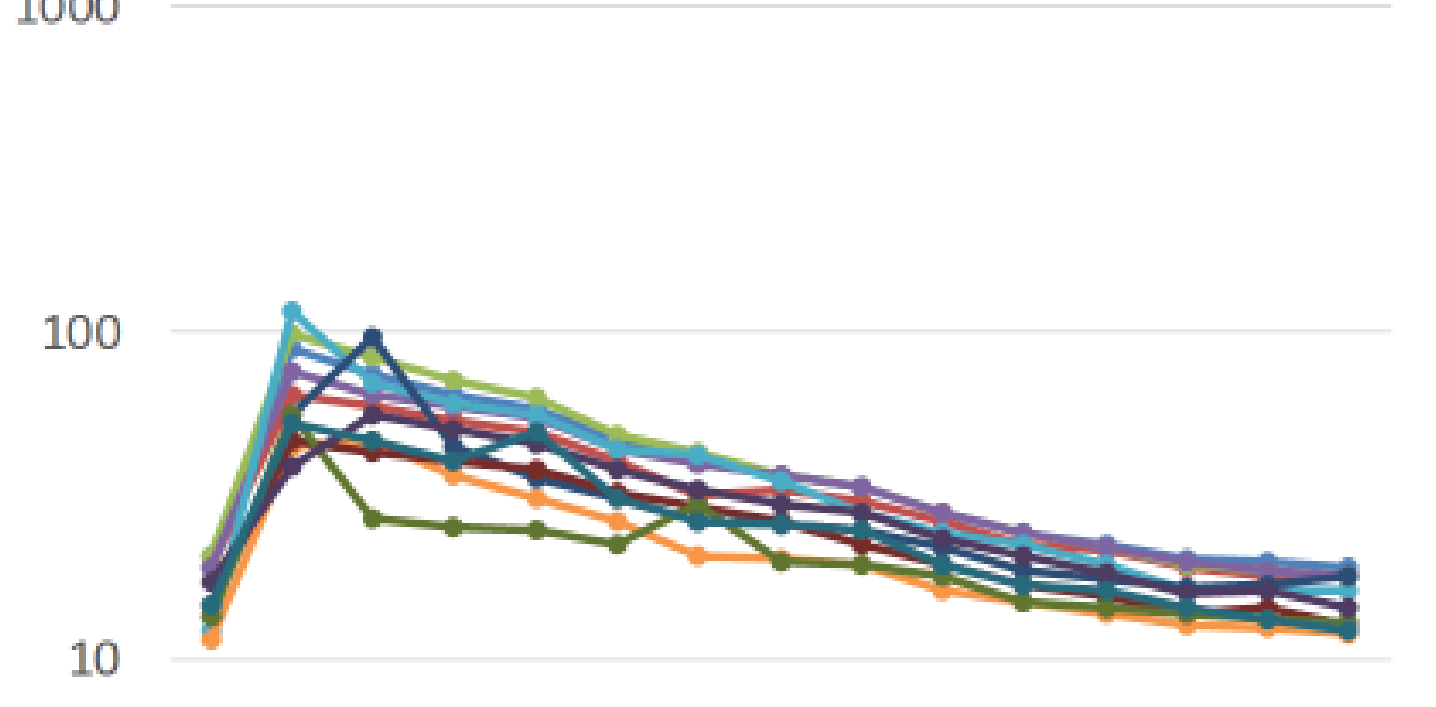

$\rightarrow$ Impact melt glass
$\rightarrow$ Shocked Basalt
$\rightarrow$ Altered Basalt
$\rightarrow$ Boulder
$\rightarrow$ Preimpact alterted Basalt
$\rightarrow$ Paleosol
$\rightarrow$ Ejecta 1
$\rightarrow$ Ejecta 2
$\rightarrow$ Ejecta 3
$\rightarrow$ Ejecta 4

1

Y La Ce Pr Nd Sm Eu Gd Tb Dy Ho Er Tm Yb Lu

\section{The ambiguity!}




\section{LHN $05-65$ Impact Melt}

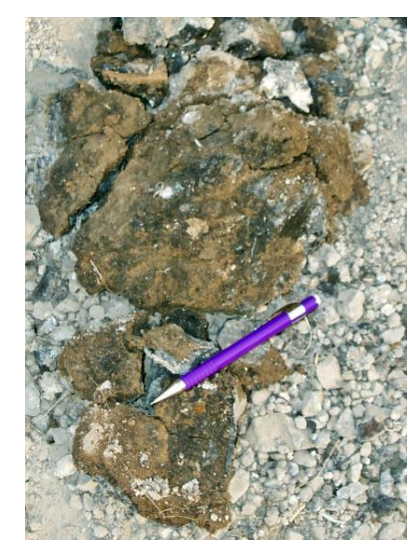

1000 > ษ ษ 흔

Cl Normalized REE Fingerprinting

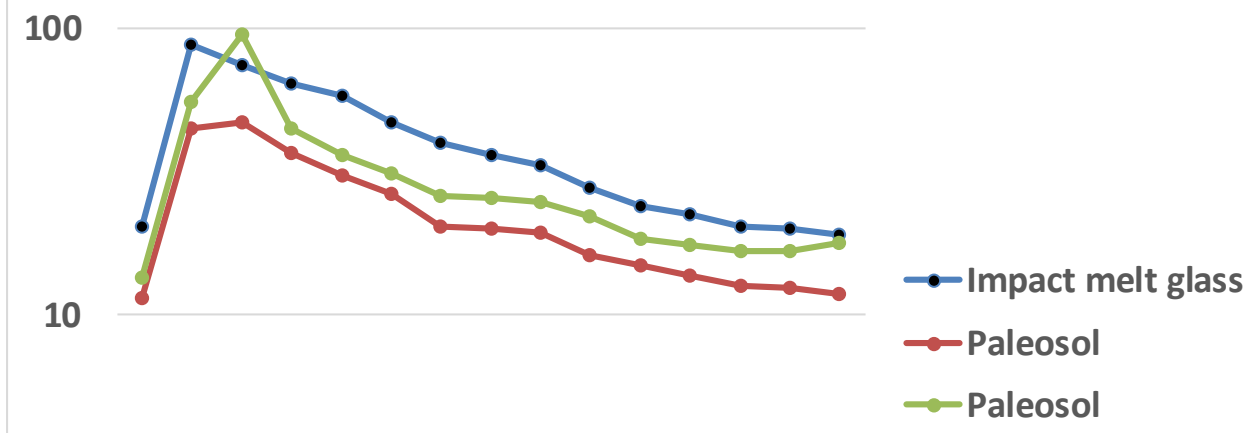

1
100

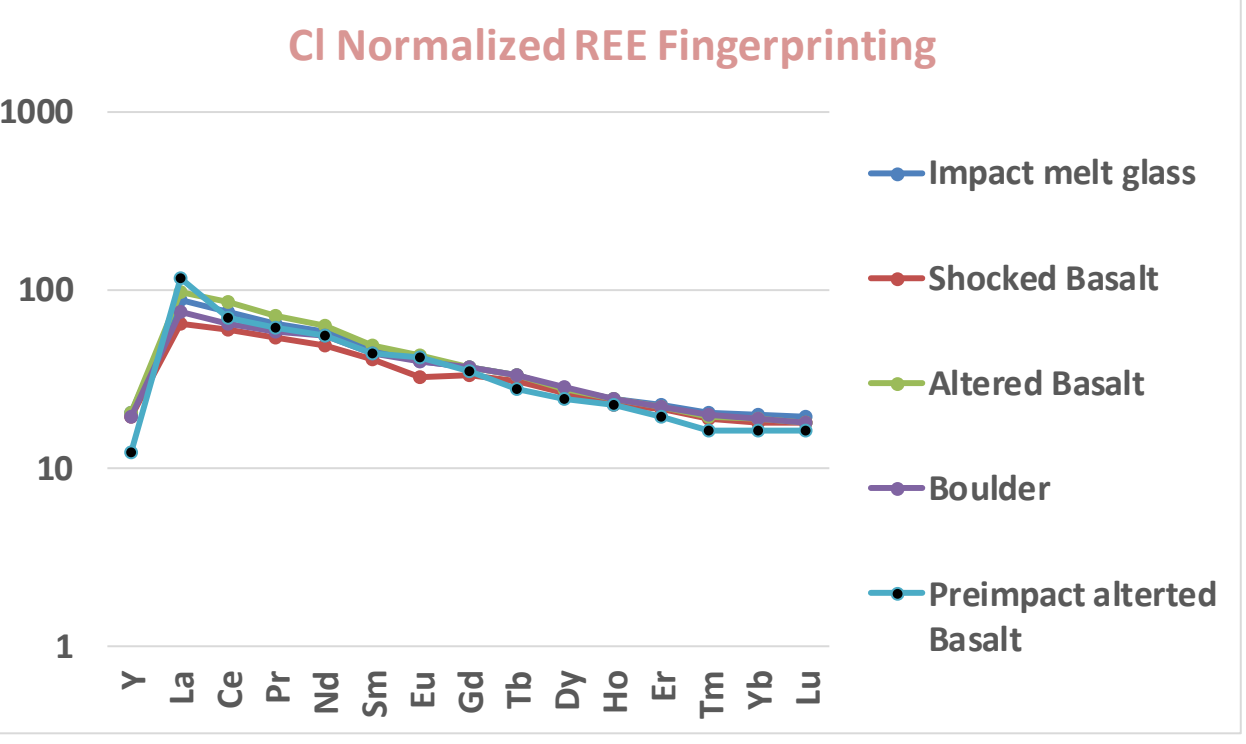

1

- Preimpact alterted

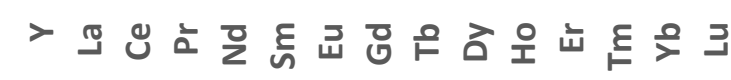

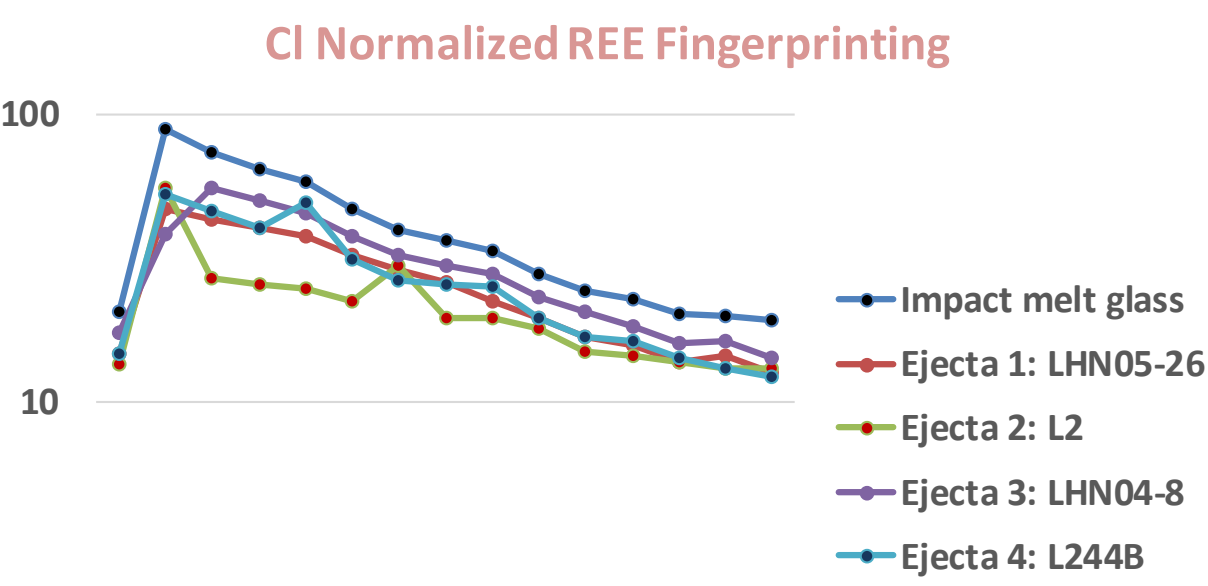

1

Y Ce Nd Eu Tb Ho Tm Lu 

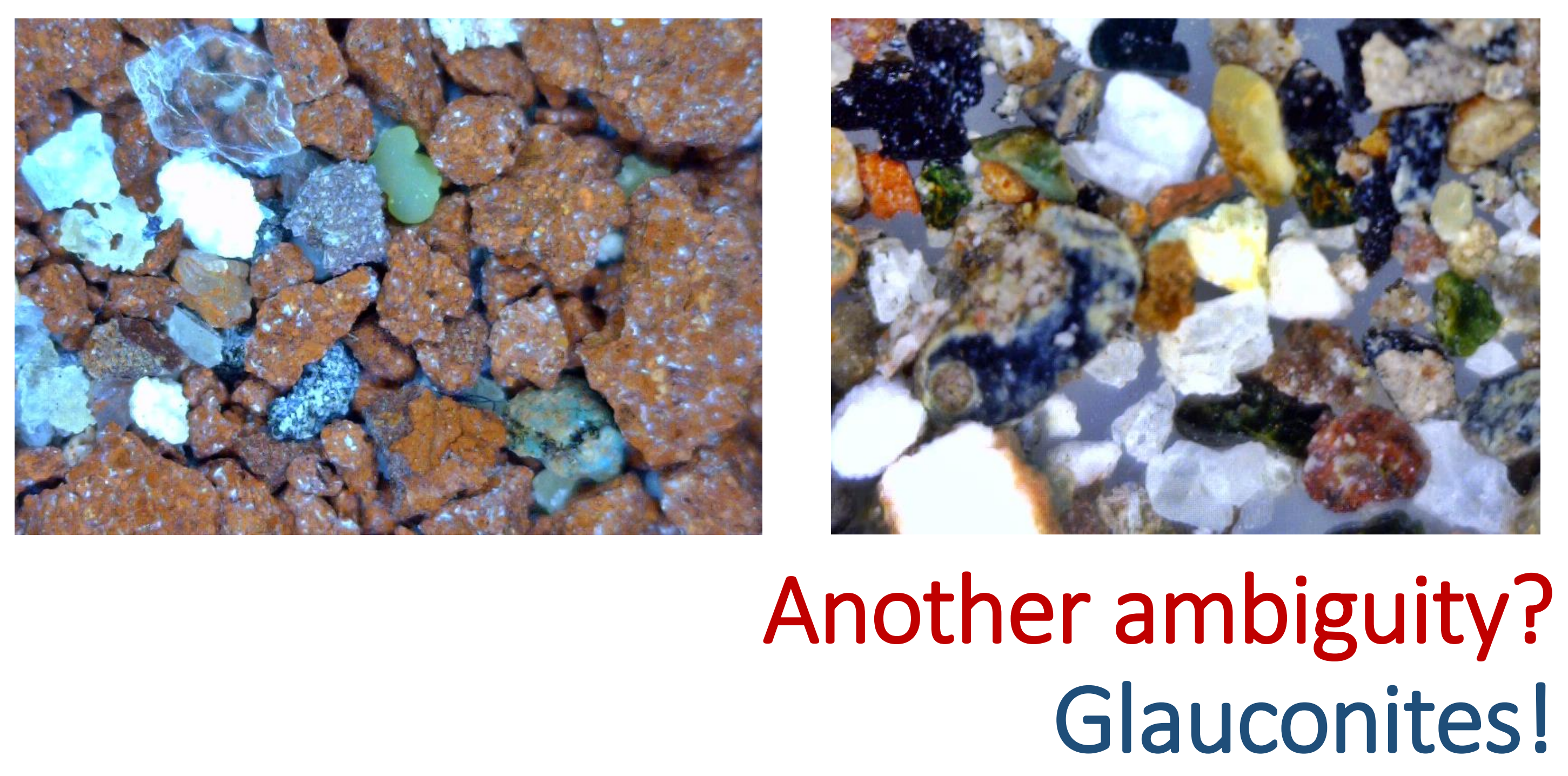
Ejecta Spherules:

Elemental Mapping by u-XRF (Tornado M4)
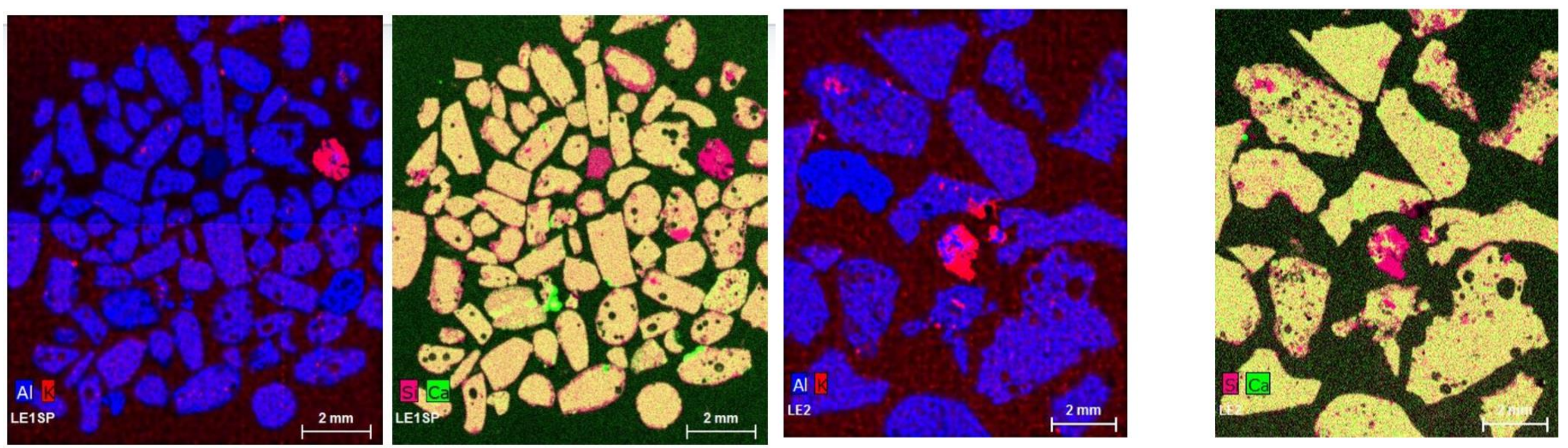


\section{SEM-EDS analysis}

Hitachi SU 70 equipped with EDAX
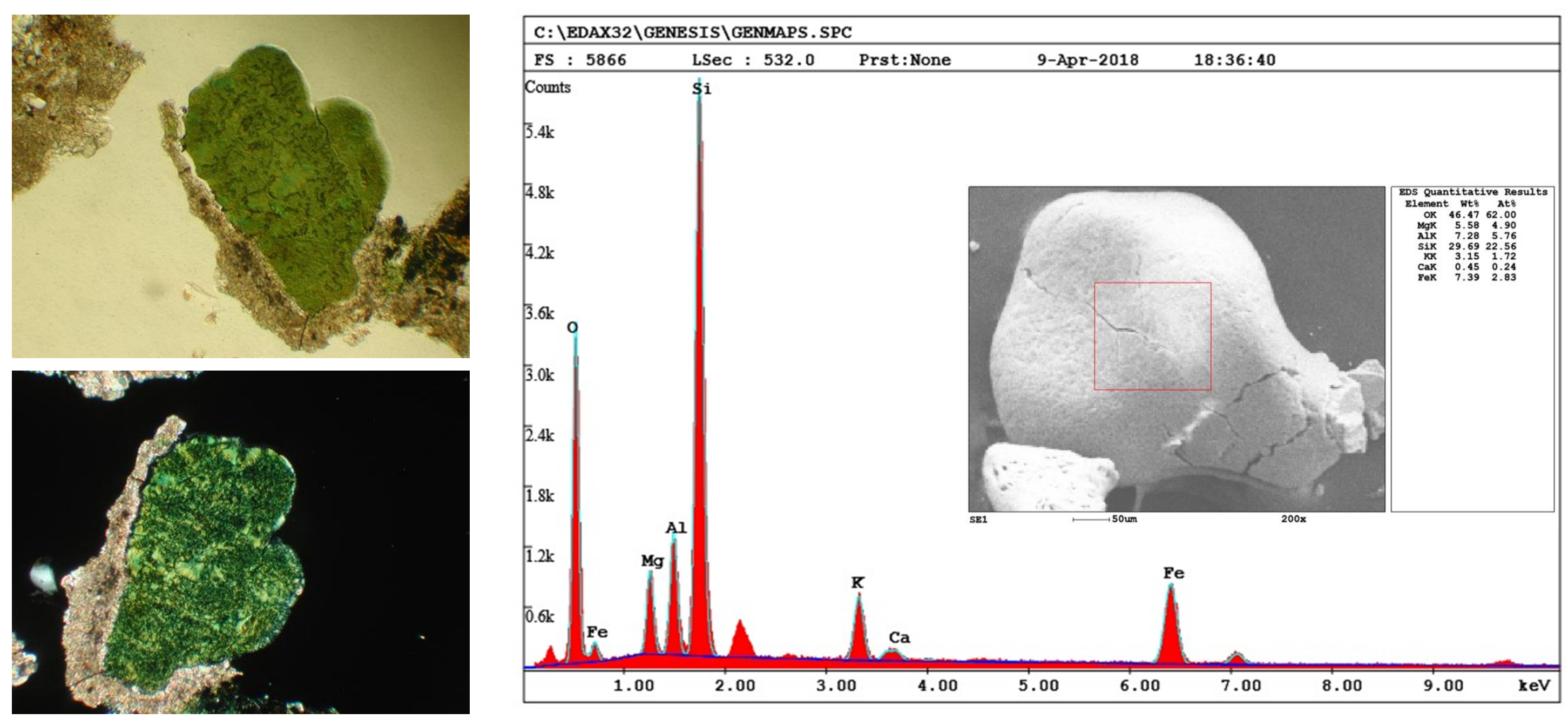


\section{The most favorable physical environment for the occurrence of glauconites:}

I. slow deposition in agitated water, and paucity of clay minerals

II. Saline, oxidizing environment

III.Sufficient organic matter is necessary to create local reducing conditions.

IV.Higher than normal amounts of iron and potassium

Apparently doesn't match with the known geological setting of Lonar Crater. 


\section{Observation:}

I. The prevalence of altered albite (NaAlSi3O8) and andesine $\left((\mathrm{Na}, \mathrm{Ca}) \mathrm{Al}_{1-2} \mathrm{Si}_{3-2} \mathrm{O}_{8}\right)$ presents some ambiguity in matching the ejecta with tholeiitic basaltic target and suggest that multiple phases of pre and postimpact alterations probably accountable for the present mineralogical assemblage.

II. Absence of explicit evidences of the projectile in the impact melt.

III. The impact cratering probably occurred on the weathered basaltic rocks or on the intertrapean sediments that was depleted in certain metals

IV. the zeolites probably developed due to post-impact alteration and finally climatic condition probably facilitated the calcification of the ejecta blanket and the preservation of the ejecta fallout.

III. Glauconites are still under investigation! 
Thanks! ..............? 